\title{
U.S. Opioid Epidemic: Impact on Public Health and Review of Prescription Drug Monitoring Programs (PDMPs)
}

\author{
Sunghee H. Boté ${ }^{*}$ \\ ${ }^{1}$ University of Illinois at Chicago, School of Public Health
}

\begin{abstract}
Objectives: In recent years, the devastating effects of U.S. opioid epidemic has been making news headlines. This report explores background information and trends on opioid misuse, overdose fatalities and its impact on public health. In addition, various efforts to improve surveillance, timeliness of data and Prescription Drug Monitoring Program (PDMP) integration and interoperability are reviewed.
\end{abstract}

Method: PubMed and internet searches were performed to find information on the U.S. opioid epidemic. In addition, searches were performed to retrieve information about PDMPs and state-specific mandates along with presentation slides and learnings from the 2018 National Rx Drug Abuse \& Heroin Summit in Atlanta, GA.

Results: It is clear that the U.S. opioid epidemic has a tremendous impact on public health including the next generation of children. Various data, surveillance \& technology-driven efforts including CDCFunded Enhanced State Opioid Overdose Surveillance Program (ESOOS) and use of telemedicine for opioid use disorder treatment aim to improve prevention, treatment and targeted interventions. In addition, PDMP integration and interoperability efforts are advancing to provide prescribers meaningful decision support tools.

Discussion: The opioid epidemic has a complex impact on public health intertwined with variable factors such as mental health and social determinants of health. Given the statistics and studies that suggest many of the illicit opioid users start with prescription opioids, continued advancement in the area of PDMP integration and interoperability is necessary. The PDMP integrated clinical decision support systems need to supply to healthcare providers access to complete, timely and evidence-based information that can meaningfully inform prescribing decisions and communication with patients that affect measurable outcomes.

Conclusion: While Prescription Drug Monitoring Programs (PDMPs) are valuable tools for providers in making informed prescribing decisions, the variable state mandates and varying degrees of integration and interoperability across states may limit their potential as meaningful decision support tools. Sharing best practices, challenges and lessons learned among states and organizations may inform strategic and systematic use of PDMPs to improve public health outcomes.

Key Words: opioid epidemic, prescription drug monitoring programs (PDMPs), prescription monitoring programs (PMPs) 
* Corresponding Author: Email: sungheebote@gmail.com

DOI: 10.5210/ojphi.v11i2.10113

Copyright @2019 the author(s)

This is an Open Access article. Authors own copyright of their articles appearing in the Online Journal of Public Health Informatics. Readers may copy articles without permission of the copyright owner(s), as long as the author and OJPHI are acknowledged in the copy and the copy is used for educational, not-for-profit purposes.

\section{Introduction}

The opioid epidemic in the United States was declared a national public health emergency on October 26, 2017 [1]. According to the Centers for Disease Control and Prevention (CDC), approximately 130 Americans die from an opioid overdose each day [2], and 46 overdose deaths involve prescription opioids [3]. The death toll from legal and illegal opioid use increased 6-fold between 1999 and 2017 [2]. Opioids accounted for approximately 68\% of all drug overdose deaths in 2017 [2], and 35\% of all opioid deaths involved prescription opioids such as methadone, oxycodone and hydrocodone [3]. Drug overdose death rate increased 137\% between 2000 and 2014 which includes $200 \%$ increase in overdose deaths involving heroin and prescription opioids indicated for treatment of pain [4]. In a study analyzing emergency department syndromic and billing data, there was a $29.5 \%$ increase in opioid overdoses in 52 areas in 45 states from July 2016 to September 2017 and a $69.7 \%$ increase in opioid overdoses in the Midwestern region during the same time period [5]. Additionally, large cities in 16 states experienced an opioid overdose increase of $54.1 \%$ [5].

Prescription opioids are generally used to treat moderate to severe pain, and some opioids can be used for treatment of diarrhea or cough [6]. Common prescription opioids are codeine, morphine, hydrocodone, oxycodone, oxymorphone and fentanyl [6]. Opioids are highly addictive, and overdose can lead to respiratory depression that can result in permanent brain damage, coma or death [6]. Naloxone is a medication that can reverse opioid overdose when administered right away [6]. Over 191 million opioid prescriptions indicated for the treatment of moderate to severe pain were dispensed in the U.S. in 2017 with wide variability among states [7]. This variability is not reflective of health status of the state [7]. Additionally, the increase in the amount of opioids dispensed in the U.S. since the 1990s does not reflect the amount of pain Americans report [7]. Some risk factors identified for prescription opioid abuse and overdose include: Receiving overlapping prescriptions using multiple prescribers and pharmacies, high daily doses of opioids, mental health disorder or history of substance abuse, and low income in rural settings [7].

Heroin is an illegal semi-synthetic opioid drug. It is estimated that approximately two out of 1,000 people in the U.S. used heroin in 2017, and the most notable increases of heroin use are in women, privately insured and higher income population [8]. Unintentional heroin-related poisoning accounted for 81,326 of emergency department visits in 2015, and drug overdoses involving heroin claimed 15,000 lives in the U.S. in 2017 [8]. The most prominent risk factor for heroin use is 
history of prescription opioid misuse [9]. According to the CDC, 75\% of new heroin users between 2000 and 2013 reported prior misuse of prescription opioids [8].

Fentanyl is a synthetic opioid which is 50 to 100 times more potent than morphine and is available as a prescription drug for the treatment of severe pain such as cancer pain [10]. While it is possible prescription fentanyl can be misused and abused, there has been a growing concern about illicit fentanyl and its analogs distributed through illegal drug markets [10,11]. The increase in fentanylrelated overdose deaths are thought to be driven by illicit fentanyl and its analogs [11]. Carfentanil, which is a fentanyl analog is used as a tranquilizer for elephants and not meant for human use [12], and it is estimated to be 10,000 times more potent than morphine and often sold mixed with heroin, cocaine or counterfeit pills [11].

\section{Method}

PubMed and internet searches were performed to find information on the U.S. opioid epidemic. In addition, searches were performed to retrieve information about PDMPs and state-specific mandates along with presentation slides and learnings from the 2018 National Rx Drug Abuse \& Heroin Summit in Atlanta, GA.

\section{Results}

\subsection{Background on the U.S. Opioid Epidemic}

Figure 1 [13] shows the three waves attributed to the rise in opioid overdose deaths. The 1990s mark the first wave with increase in opioid prescriptions with notable increase in opioid overdose deaths around 1999 [2]. There was an increased awareness and focus on treatment of chronic pain around this time, and an Institute of Medicine report attributed the increase in prevalence of chronic pain during the 1990s to "greater patient expectations for pain relief, musculoskeletal disorders of an aging population, obesity, increased survivorship after injury and cancer, and increasing frequency and complexity of surgery. [14]" Pharmaceutical companies continued to proliferate in manufacturing opioids including sublingual, transdermal, extended-release and nasal spray formulation products, and some pharmaceutical manufacturers marketed opioids by minimizing addiction potential and promoting off-label uses of opioid indicated for acute breakthrough pain in cancer patients [14].

The second wave began around 2010, and it is characterized by a significant rise in heroin-related overdose deaths [2,14]. Between 2010 and 2015, heroin overdose deaths tripled [14]. The last wave which began in 2013 and continues today is characterized by a pronounced increase in synthetic opioid-related overdose deaths, predominantly related to the rise in illicit fentanyl [2]. Overdose deaths related to fentanyl analogs increased by $540 \%$ between 2013 and 2016 [14]. 


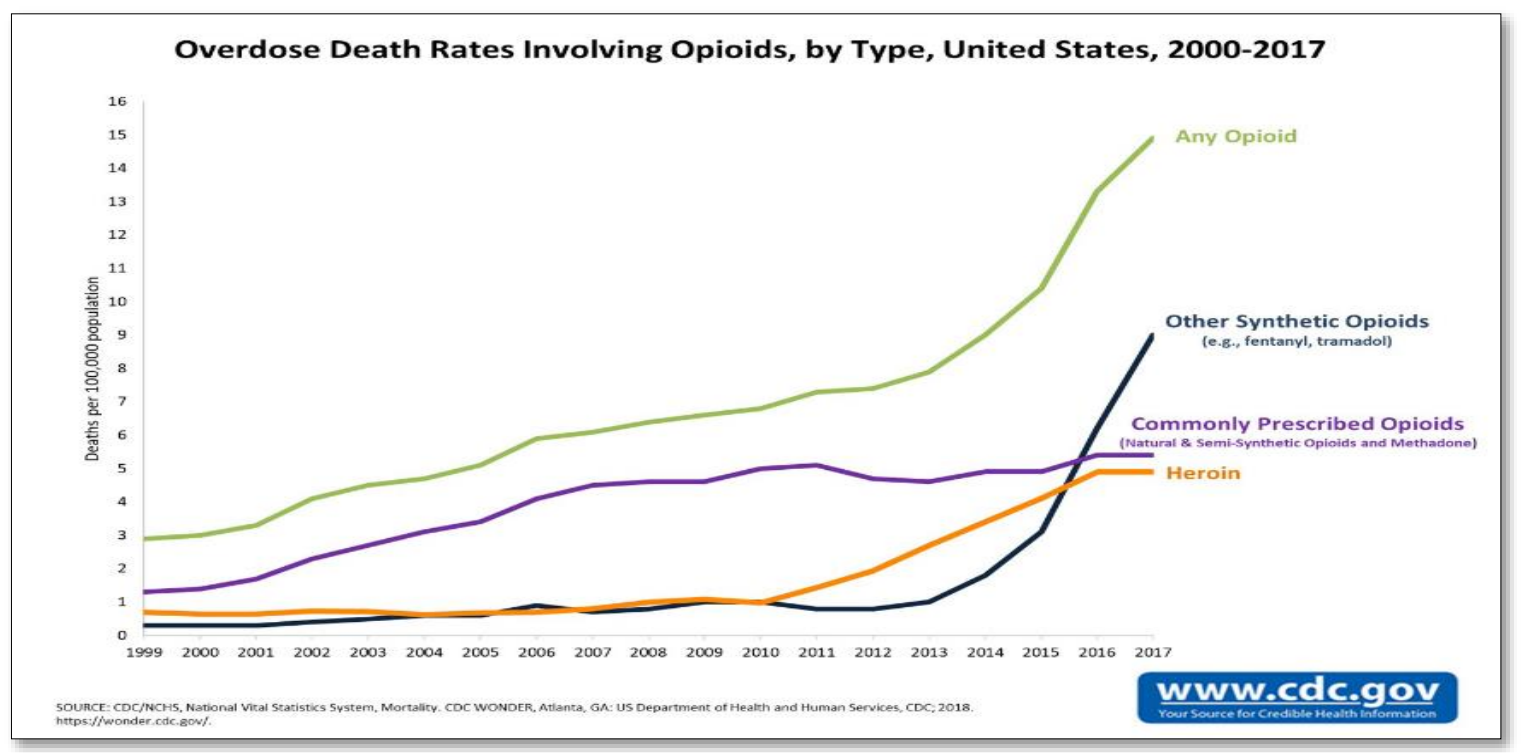

Figure 1: Overdose Death Rates Involving Opioids, by Type, United States, 2000-2017 Source: CDC [13]

\subsection{Impact on Public Health}

CDC announced that U.S. life expectancy declined in 2017 for the third year in a row, driven by drug overdose deaths and suicides [15]. The average life expectancy decreased from 78.9 in 2014 to 78.6 in 2017, and it is the longest sustained life expectancy decline since 1915 through 1918 during World War 1 and a flu pandemic that killed estimated 50 million worldwide $[15,16]$. There has been a 19\% increase of overdose deaths among teenagers from 2014 to 2015, and blood-born infection transmission from drug injection equipment sharing continues to be a problem [17]. According to CDC, estimated one in 23 women and one in 36 men using drugs via injections will have HIV diagnosis in their lifetime, and opioid use is thought to have contributed to hepatitis $\mathrm{C}$ infection transmission which is estimated to have tripled between 2000 and 2015 [17]. Furthermore, infants exposed to opioids in utero are at a risk of neonatal abstinence syndrome (NAS), and prenatal exposure to opioids have been associated with poor fetal growth, preterm birth or still birth [18]. The incidence of NAS is reported to have increased $433 \%$ between 2004 and 2014, and this translates to increase from 1.5 per 1,000 hospital births to 8.0 per 1,000 hospital births [18].

Feder, Letourneau \& Brook [19] address at least five ways the opioid epidemic may affect and harm health and safety of children and adolescents: Intentional or accidental ingestion of prescription drugs, misuse of opioids in pregnancy resulting in problems such as NAS, inadequate prenatal care and low birth weight, impaired parenting and attachment due to parental opioid misuse, material deprivation due to family finances being spent on drugs, and extended separation such as foster care due to parent's incarceration, drug treatment or death. The opioid epidemic has a complex impact on public health intertwined with variable factors such as mental health and social determinants of health. Studies suggest links between childhood trauma and substance use 
disorder [20]. A study of urban primary care patient sample by Khoury, Tang, Bradley, Cubells, \& Ressler [20] concluded "data show strong links between childhood traumatization and SUDs, and their joint associations with PTSD outcome." Studies also suggest there is a history of major depressive disorder in greater than $50 \%$ of patients with opioid use disorder, and opioid use disorder was associated with risk of suicidal ideation and suicide [21].

Dasgupta, Beletsky \& Ciccarone [14] "posit that the crisis is fundamentally fueled by economic and social upheaval, its etiology closely linked to the role of opioids as a refuge from physical and psychological trauma, concentrated disadvantage, isolation, and hopelessness. Overreliance on opioid medications is emblematic of a health care system that incentivizes quick, simplistic answers to complex physical and mental health needs." The authors state the increase in opioid prescription is not solely to blame for the current opioid epidemic, but various structural factors contributed to it [14]. For example, individuals may somaticize social disasters and economic hardships into physical pain, and childhood trauma is associated with increased opioid use in later years [14]. The counties with highest overdose rates have lowest levels of social capital, and individuals living in low socioeconomic areas have increased likelihood of developing chronic pain after automobile accidents which is mediated by stress response genes [14]. The authors concluded there is an urgency to integrate clinical care and addressing individuals' structural environments [14]. Park, Lin, Hosanagar, Kogowski, Paige \& Bohnert [22] state "opioid dosage was the factor most consistently analyzed and also associated with increased risk of overdose. Other risk factors include concurrent use of sedative hypnotics, use of extended-release/longacting opioids, and the presence of substance use and other mental health disorder comorbidities."

The opioid epidemic also has a significant impact on the safety of first responders when they come into contact with highly potent and fast-acting fentanyl and fentanyl analogs during their routine emergency responses [23]. Thirty-three pounds of fentanyl seized in Boston is estimated to be enough to wipe out the entire state of Massachusetts [23]. First responders must be trained to recognize signs of exposure such as disorientation, respiratory distress, coughing, sedation, and cardiac arrest; they also need to receive adequate training, wear gloves, masks, eye protection and be prepared to administer opioid overdose reversal drug naloxone when necessary [23].

CDC estimates the annual "economic burden" of prescription misuse in the U.S. including healthcare cost, productivity loss, addiction treatment and cost of criminal justice is $\$ 78.5$ billion [24]. The Public Broadcasting Service [25] News Hour segment titled "How the opioid crisis decimated the American workforce" explored through interviews, the devastating impact of opioid crisis on the northeastern Ohio families and workforce. The segment revealed that employers are having difficulty finding skilled employees that can pass drug tests, and Alan Krueger from Princeton University stated in the interview, "For both prime-age men and prime-age women, the increase in prescriptions over the last 15 years can account for perhaps 20 percent of the drop in labor force participation that we have seen [25]."

According to Burke, Goplerud \& Hartley [26], entertainment, recreation, food and construction industry have higher than average relative prevalence of substance use disorder; costs of missed work per employee range from $\$ 187$ to $\$ 3,941$ annually depending on the industry sector [26]. Additionally, the job turnover rate is $36 \%$ vs. $25 \%$ in general workforce when employees have 
untreated or active substance use disorder (SUD) with annual per capita cost from $\$ 512$ to greater than $\$ 4,000$ [26]. In 2014, the cost of healthcare for an employee with SUD was $\$ 2,198$, and cost of healthcare for an employee with pain medication use disorder was approximately double at $\$ 5,586$, primarily driven by emergency department use [26]. Employers' investment in treatment and workers in recovery for one year show improvement and return to baseline [26].

\subsection{Prevention, Treatment, Reversal of Opioid Overdose}

The Centers for Disease Control and Prevention (CDC) promotes the following approach in opioid overdose prevention [27]:

- Improve Opioid Prescribing: In 2016, CDC published the "CDC guidelines for Prescribing Opioids for Chronic Pain" which covers three conceptual areas: When to initiate or continue opioid therapy for treatment of chronic pain, selection of opioid, dosage, duration, follow-up and discontinuation of opioid therapy, and assessment of risk and addressing harm from opioid use [28,29]. This guideline aims to reduce the gap in opioid prescribing training for primary care providers and address safer and more effective treatment of chronic pain outside of active cancer treatment, palliative and end-of-life care [29].

- Prevent Opioid Use Disorder: Promote various ways to help reduce opioid exposure and opioid use disorder (OUD) including the use of prescription drug monitoring program (PDMP), patient education on safe storage and disposal of prescription opioid medications, and prescription insurance prior authorization/quantity limit strategies [30]. Additionally, funding of "Prevention for States" program for 29 states provides resources and support for interventions to prevent prescription drug overdoses, and CDC's RxAwareness campaign shares resources to educate patients and families about the risk of prescription opioids and the impact and cost of overdose [30].

- Treat Opioid Use Disorder: Expand access to evidence-based treatments such as medication-assisted treatment (MAT) in addition to behavioral therapy and counseling [31]. Substance Abuse and Mental Health Services Administration (SAMHSA) makes "Behavioral Health Treatment Services Locator" available for patients to confidentially and anonymously find treatment facilities [32].

- Reverse Overdose to Prevent Death: Expand access to life-saving opioid overdose reversal medication naloxone through training of and use by law enforcement officials and emergency medical staff, local organizations, and standing orders for dispending at the pharmacies [33].

In addition, the U.S. Department of Health and Human Services (HHS) announced its 5-Point Strategy in response to the U.S. opioid epidemic [34]:

- Better Prevention, Treatment and Recovery Services: Grants in support of access to treatment, prevention, recovery and facilitate treatment coverage through state Medicaid programs [35]. 
- Better Data: Support of more timely and accelerated data and reporting including CDC drug overdose data and the Centers for Medicare and Medicaid Services (CMS) Medicare opioid prescription mapping tool [36].

- Better Pain Management: Promote evidence-based pain management methods including identification and recommendation proposals to address gaps/inconsistencies and establishing Healthy People 2020 Objectives [37].

- Better Availability of Overdose-Reversing Drugs: Improve access to overdosereversing naloxone drugs to individuals such as those receiving prescription opioid pain medications, illicit drugs such as heroin or fentanyl, and family and friends of individuals with opioid use disorder [38].

- Better Research: Support pain and addiction research to ensure evidence-based policies, inform clinical practitioners and reduce prescription opioid use [39].

In addition to the approaches and strategies outlined by CDC and HHS, there is an increased emphasis on harm reduction such as syringe service programs to prevent transmission of hepatitis $\mathrm{C}$ infection and human immunodeficiency virus infections [4]. Furthermore, education and access to treatment need to be expanded to address and prevent a baby being born with NAS every 15 minutes [40]. Public health and law enforcement agencies, medical examiners and coroners working collaboratively can improve detection of drug overdose outbreaks related to illicit opioids allowing for expedited response and targeted intervention [4].

\subsection{Data, Surveillance \& Technology-Driven Initiatives}

There are various data, surveillance and technology-driven initiatives in response to the opioid epidemic. The initiatives aim to research and develop targeted interventions, strengthen access to opioid use disorder treatment, and develop strategies and tools for "faster data" to track and response to opioid overdoses. Examples are CDC-funded Enhanced State Opioid Overdose Surveillance Program (ESOOS) and the use of telemedicine technology for substance use disorder/behavioral health treatments [41].

\subsubsection{CDC-Funded Enhanced State Opioid Overdose Surveillance Program (ESOOS)}

The ESOOS program funded 12 states in September 2016 with 20 states and District of Columbia added in September 2017 [41]. The first strategy for ESOOS is syndromic surveillance using emergency department data for timely non-fatal opioid overdose reporting, and this is achieved by detecting sharp increases or decreases [41]. The second strategy is reporting on fatal opioid overdose through State Unintentional Drug Overdose Reporting System (SUDORS) that captures detailed death scene investigation and toxicology information; other risk factors related to the fatal overdoses are also captured [41]. This strategy can detect and inform newly emerging substances, common drug combinations, and helps identify risk factors and circumstances that may be associated with fatal overdoses [41]. Lastly, the third strategy is widespread dissemination of findings to key stakeholders to improve local and state public health prevention and response efforts, and trends are tracked to inform national policy [41]. 
Singleton, Saavedra \& Broad [42] presented "States with Fast Data: Lessons Learned from Kentucky, New Mexico and Wisconsin" at the 2018 National Rx Drug Abuse \& Heroin Summit. Kentucky, New Mexico and Wisconsin are three of the states receiving the ESOOS grant [42]. Kentucky made efforts to improve drug overdose surveillance reporting including better drug specificity on death certificates, and while the process is slow, Kentucky is making progress in reducing lag time between death events and reporting [42]. This is done by making improvements to Drug Overdose Fatality Surveillance System (DOFSS) such as adding a full-time abstractor to decrease case initiation to completion time, automation of toxicology reporting, database platform change and emergency medication services integration [42]. For example, the mean time from death to case initiation decreased from 15 months in 2014 to 4 months in 2017, and the mean time from receiving coroner report to entry in DOFSS decreased from 87 days in 2016 to 27 days in 2017 [42]. Emergency departments (ED) voluntarily participate in syndromic surveillance of nonfatal overdoses, and providers who elect to participate in Kentucky's ED Sys forward messages to KY Health Information Exchange (KHIE) where messages are de-identified and batches transmitted to CDC BioSense platform [42]. Median days between admit to first message, chief complaint, diagnosis in Electronic Surveillance System for the Early Notification of Communitybased Epidemics (ESSENCE) decreased from days to hours between May 2016 to March 2018 [42]. The emergency department data has its challenges; participation is voluntary with the primary incentive being Meaningful Use and dropped feeds and system lags are not resolved quickly [42].

The New Mexico Department of Health learned through the ESOOS program that buy-in of emergency medical system (EMS) data managers, providing feedback to emergency medical technicians (EMT), and discussion with other states utilizing EMS data for surveillance is vital in establishing standard definitions for suspected overdose cases and reducing missing information from the field [42]. New Mexico also faced challenges due to lack of uniformity in ED data and found communicating to the ED staff about how the data collected is used can help bridge the gap [42].

In Wisconsin, the Wisconsin Ambulance Run Data Systems (WARDS) which has been in use since 2010 captures $90 \%$ of EMS data [42]. While the data submission is mandatory within seven days of incident, it is challenging to work with the data due to decentralization and free text data entry [42]. The ambulance data is linked with multiple data systems for hospital discharge and death certificate information, and the future goal is integration of PDMP and National Violent Death Reporting System (NVDRS) [42]. Additionally, while 84\% of hospital ED submit syndromic surveillance data through BioSense platform funded through Meaningful Use, the large volume of data reduces system performance, and historic data upload and data quality validation is crucial and a challenge [42]. Despite the challenges, local health departments were educated on using the syndromic data, and a pilot alert system was developed [42]. Wisconsin Department of Public Health also worked through challenges related to decentralization of toxicology testing and data collection from corners and medical examiners, and as of the presentation in April 2018, death investigation reports were available for $95 \%$ of opioid fatalities [42]. 


\subsubsection{Telehealth}

It is estimated that less than $20 \%$ of individuals who need treatment for substance use disorder receive it, and access to behavioral health care and opioid use disorder treatment is particularly challenging in rural areas and correctional facilities [43]. Telehealth may bridge the gap in underresourced areas by delivering virtual behavioral health and education services most frequently using live video but also using emails, text messages and telephony; it can also support rural clinicians in need of specialty consultation [43]. According to Yellowlees [44], virtual care may have advantages for the patient given s/he can build relationships with providers outside of the residing community and may provider better environment to discuss awkward, embarrassing or stigmatizing topics. Additionally, transcription and translation services can be integrated [44]. In a 2 year-retrospective data analysis study of individuals diagnosed with opioid use disorder by Zheng, et al. [45], there was no significant statistical difference in additional substance use, average time to 30 and 90 days of abstinence and treatment retention rates between telepsychiatry buprenorphine MAT interventions compared with face-to-face MAT treatments.

\section{Discussion}

\subsection{Prescription Opioid Utilization in the U.S. \& Changing Opioid Prescribing Practices}

The Washington Post published an article on March 15, 2017 written by Humphreys [46] titled "Americans use far more opioids than anyone else in the world." In this article, Humphreys notes that according to the United Nations data of top 25 opioid consuming countries in the world, the United States is the heaviest consumer of opioids in the world [46]. According to the U.N. report, 99\% of world's supply of hydrocodone is consumed by Americans; this disparity of heavy opioid consumption does not appear to be related to the aging population, because other countries such as Australia and Italy have higher proportion of population 65 years and older [46]. In another Washington Post article, Humphreys [47] explores if the high consumption of opioids in the U.S. is due to unusually high levels of pain. According to a 2008 research, the age standardized prevalence of chronic pain in the U.S. was similar to Italy and France; however, the opioid consumption per capita was approximately 6 to 8 times higher in the U.S. compared to Italy and France [47]. Humphreys [46,47] points out in both articles that a notable difference in the U.S. compared to other countries is the lack of constraints placed on the pharmaceutical manufacturers to market and promote their products to patients and prescribers, as well as to lobby and donate to political causes and regulatory bodies.

In the 2017 report of Office of Inspector General (OIG), opioid prescription records from 2016 were analyzed as part of a strategy to protect Medicare Part D beneficiaries from prescription drug abuse and harm [48]. The analysis found that in 2016, one in three Medicare Part D recipients received at least one prescription opioid, and approximately 500,000 beneficiaries received high doses of opioid defined as greater than $120 \mathrm{mg}$ morphine equivalent dose (MED) per day for at least 3 months [48]. Additionally, approximately 400 prescribers had prescribing habits considered outside the norm warranting further scrutiny [48]. Furthermore, the study found that approximately 70,000 beneficiaries were at serious risk by receiving very high doses of opioid [48]. Approximately 22,000 beneficiaries appeared to be doctor shopping based on the number of 
prescribers and pharmacies used to obtain these medications and indicated potential drug seeking behavior for nonmedical use or diversion; they may also be instances of stolen beneficiary number or that the beneficiary's care is not closely monitored or coordinated by the providers [48].

The overall opioid prescribing rate in the U.S. declined from 2012 to 2017 as illustrated in Figure 2 [49]. In 2017, the rate declined to the lowest in more than 10 years; however, opioid prescribing rate is still at 58.7 prescriptions per 100 persons totaling more than 191 million prescription in 2017 [49]. Furthermore, prescribing rates remain high in certain areas of the country. According to $\mathrm{CDC}, 16 \%$ of counties dispensed enough opioid prescriptions for every person with some counties at rates seven times higher than the overall national rate [50].

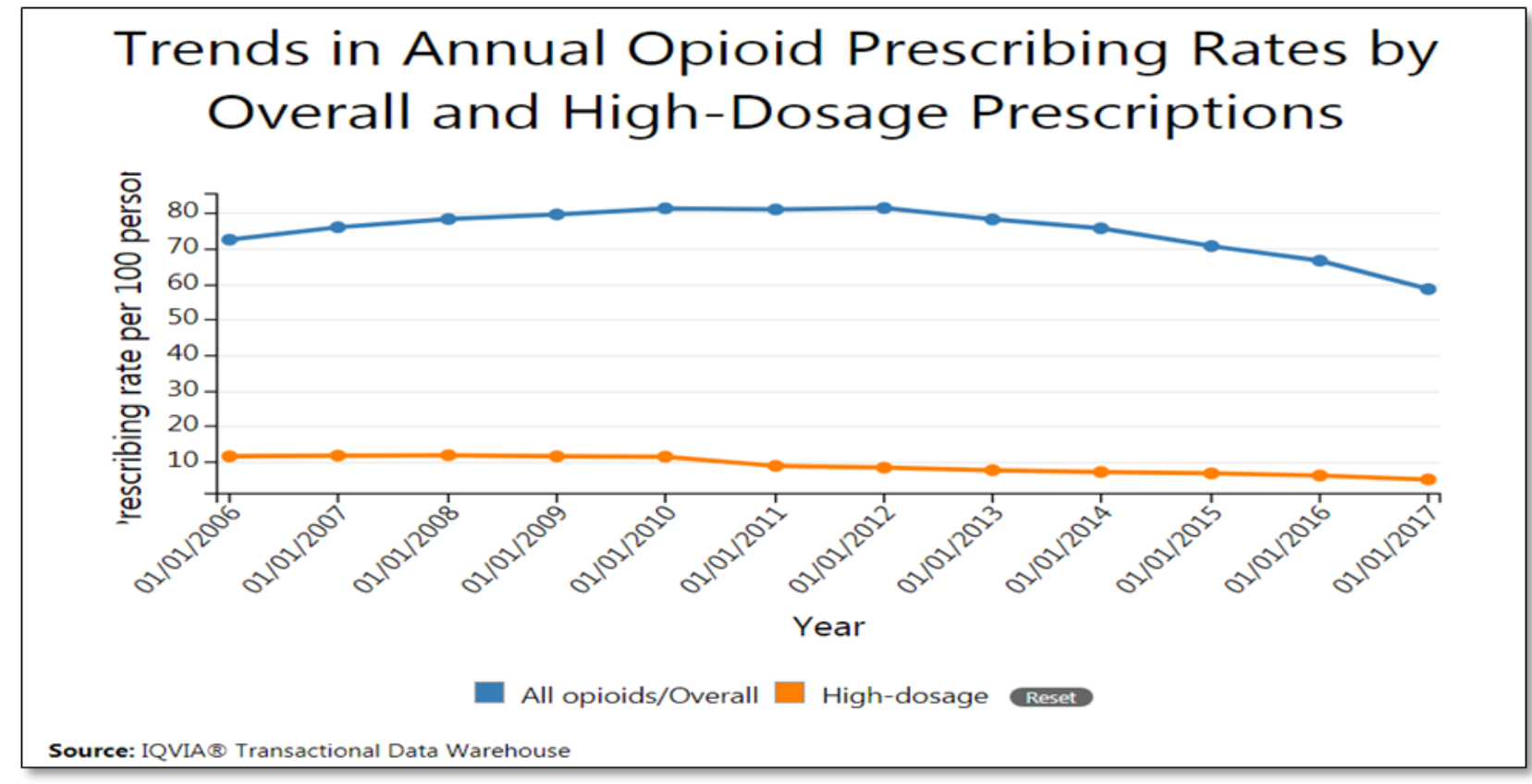

Figure 2: Trends in Annual Opioid Prescribing Rates by Overall and High-Dose Prescriptions Source: CDC [49]

Nelson, Juurlink, \& Perrone [51] stated "the chronic, relapsing nature of opioid addiction means most patients are never 'cured,' and the best outcome is long-term recovery. The lifelong implications of this disease far outweigh the limited benefits of opioids in the treatment of chronic pain, and in many cases the risks inherent in the treatment of acute pain with opioids. The encouraging finding of declining opioid initiation rates should be tempered by the increasing rates of nonmedical opioid use disorders and the limited utilization of treatment programs. Although multifaceted approaches are needed to successfully address the opioid epidemic, an important step is to start at the beginning and keep opioid-naive patients opioid naive."

\subsection{Prescription Drug Monitoring Program (PDMP)}

Prescription Drug Monitoring Programs (PDMPs), also referred to as PMPs are state-level electronic databases used to track controlled substance prescription data [52]. PDMPs are tools for 
providers to make informed prescribing and dispensing decisions based on the patient's utilization, and PDMPs have the potential to help improve patient safety and public health [52]. Despite the mixed findings, PDMP evaluations demonstrated prescribing behavior changes, reduction in utilization of multiple providers, and decrease in substance abuse treatment admissions [52]. The benefit of PDMP is only realized when the provider actively utilizes the information in the PDMP. Each state implements PDMP in ways it sees fit; some states mandate the use of PDMPs in established circumstances such as prior to prescribing or dispensing controlled substances [52]. In addition, while pharmacists enter prescription data into the state's PDMP, the data submission intervals may range from minutes, days, weeks or month [52]. Data collected may also be used by state health departments, state insurance programs, healthcare licensure boards and law enforcement agencies as shown in figure 3 below [52].

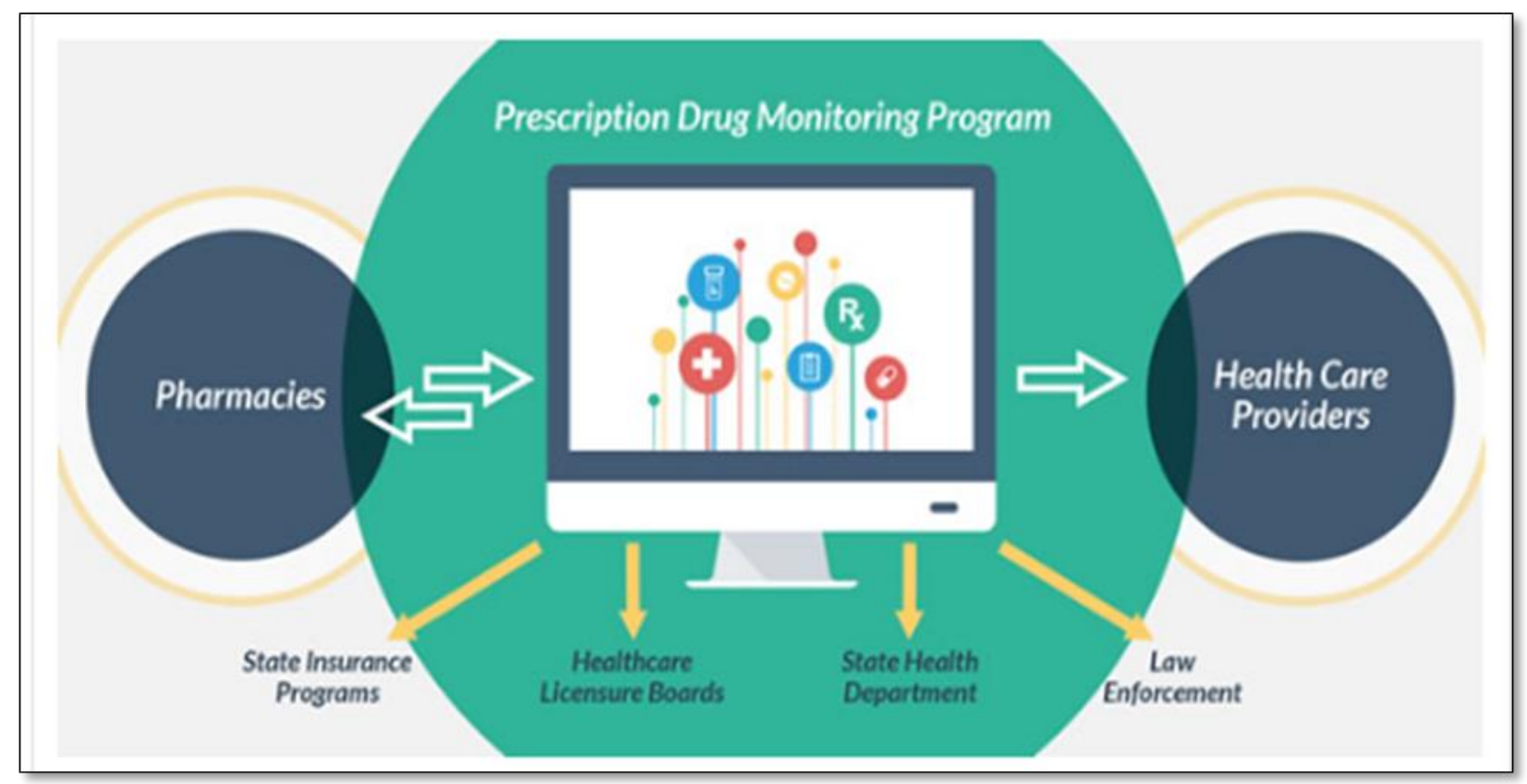

Figure 3: Prescription Drug Monitoring Program (PDMP) Source: CDC [52]

When opioid medications are prescribed, there needs to be a mutual understanding between the provider and the patient that long term use of opioids can result in physiological dependence, particularly when opioid are prescribed for non-cancer diagnoses [53]. In addition to pain agreement to ensure mutual understanding and expectation of risks, benefit and responsible medication use, PDMP is a tool providers can use to make informed prescribing decisions [53]. For example, PDMP can provide information to confirm lost prescriptions are in fact lost and not being diverted [53]. In addition, PDMP can inform the prescriber about the patient's controlled substance utilization including those from other prescribers filled at multiple pharmacies and resolve concerns regarding early fills by checking the previous fill dates submitted by the pharmacy [53].

The following is an example of an institutional protocol implementation including a PDMP consult. According to Kolodny [54], dentistry accounted for $28.9 \%$ of opioid prescriptions. 
Additionally, more opioids are prescribed for teenagers by dentists compared with all other specialties [55]. Furthermore, Miech, Johnston, O’Malley, Keyes \& Heard [56] concluded that the "use of prescribed opioids before the 12th grade is independently associated with future opioid misuse among patients with little drug experience and who disapprove of illegal drug use." Given these concerns, the University of Minnesota, School of Dentistry has established a protocol for teaching and clinical practice to use non-opioid analgesics as first-line agent and use opioid at the lowest effective dose when required [54]. As part of the protocol, clinicians must consult the PDMP prior to issuing an opioid prescription, and reasons for deviation from the protocol are documented [54].

\subsubsection{Prescription Drug Monitoring Program (PDMP) Mandates by State}

As previously mentioned, PDMPs are state-level electronic databases implemented and regulated by each state [52]. As of 2018, 41 states mandate providers to use the PDMP; however, the mandated circumstances vary including drugs it tracks, frequency, and exemption parameters [57]. For example, Arizona Statute A.R.S. § 36-2606 mandates medical practitioners who possess DEA license to review patient's record in the PDMP for preceding 12 months prior to prescribing schedule II controlled substances or a benzodiazepine [58]. Additionally, effective April 26, 2018, dispensing pharmacists working in an outpatient setting and whose employer has a U.S. DEA registration must review patient records in the PDMP for preceding 12-month prior to dispensing schedule II controlled substances [58]. The State of Michigan recognizes gabapentin as schedule $\mathrm{V}$ controlled substance and requires gabapentin prescription data submission to its PDMP, Michigan Automated Prescription System effective January 4, 2019 [59].

According to PEW [57], comprehensive mandates that apply to all prescribers and to all initial opioid prescriptions at minimum are associated with reduction in utilization of multiple prescribers, pharmacies and number of opioid prescriptions. A study by Rasubala, Pernapati, Velasquez, Burk, \& Ren [60] found that since the mandate to consult PDMP prior to opioid prescribing in New York State, there has been a 78\% reduction in absolute quantity of opioids prescribed by dentists over 3 months from 5096 pills to 1120. Paulozzi, Kilbourne, Desai [61] concluded PDMPs appear to have minimal effect on the overall opioid consumption and overdose mortality rate, and improvement in the use of PDMP data to positively impact overdose rate is necessary. Patrick, Fry, Jones \& Buntin [62] determined that states with prescription drug monitoring programs reduced opioid-related overdose deaths by 1.12 per 100,000 population and the states with more robust program characteristics such as tracking larger number of drugs of abuse potential and updating the PDMP data at least weekly had a higher reduction in mortality.

\subsubsection{Prescription Drug Monitoring Program (PDMP) Challenges, Integration, Interoperability and Improvement Efforts}

While PDMPs can be useful tools for providers, the limited data sharing across states limit their usefulness particularly for providers working near state borders. In addition, lack of PDMP data integration with health information systems such as health information exchange (HIE), electronic health record (EHR) and pharmacy dispensing software (PDS) systems present workflow challenges and barriers [63]. Some specific deterrents for providers include the need for clinicians 
to log in for PDMP search, time it takes for the search to return the records requested, and limited understanding on using data that is returned from the search [64]. The Substance Abuse and Mental Health Services Administration (SAMHSA) funded the PDMP Electronic Health Records Integration and Interoperability Expansion (PEHRIIE) program in nine states during fiscal years 2012 to 2016 [63]. This effort aimed to address PDMP data integration challenges, better inform clinical decisions through interstate data sharing and promote point of care interventions thus improvement in outcomes $[63,64]$. Figure 4 depicts general EHR, pharmacy and PDMP integration established in the PEHRIIE program [63].

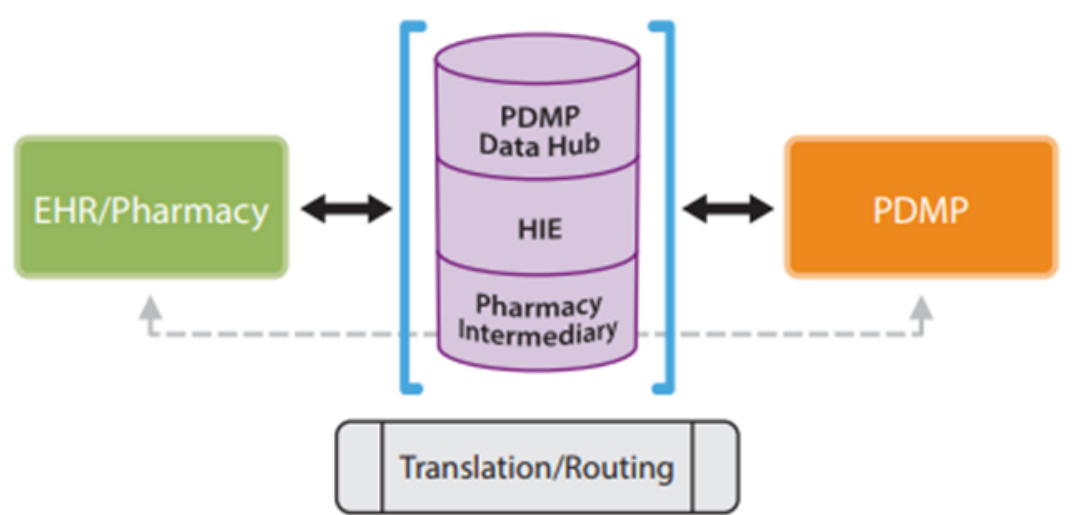

EHR/Pharmacy Exchange Standard: HL7V2 NCPDP SCRIPT ASAP Web Services
PDMP Standard: PMIX-NIEM
Variant 1: Intermediary provides translation functionality

Variant 2: Translation is handled at HIE, providing mapping to PMIX from native EHR standards

Variant 3: Interface engine provides functionality to send PMIX message derived from EHR/Pharm standards

*Solution is agnostic to transport

Source: Office of the National Coordinator (ONC) for Health Information Technology and SAMHSA. Available at: http://wiki.siframework. org/file/detail/Finalized+Solution+Plan.pptx

Figure 4. EHR, Pharmacy, and PDMP Integration Source: CDC [63]

Five of eight states were able to integrate PMDP reports with PDS systems (local or statewide), HIEs or EHRs [63]. Three states, Kansas, Washington and Illinois had data to examine possible impact of the program; Kansas completed integration of PDMP with the Via Christi Health Network [63]. Solicited reports by Via Christi Health Network providers increased greater than sevenfold from 31,156 in 2013 to 223,000 in 2015 [63]. As a comparison, statewide PDMP reports solicited excluding Via Christi prescribers increased $183 \%$ during the same time period from 23,171 in 2013 to 65,242 in 2015 [63]. The State of Washington completed PDMP integration with its HIE, One Health Port and the Emergency Department Information Exchange (EDIE) late 2014 [63]. During the 2014 calendar year, 26,546 reports were provided via EDIE; it increased 80fold in 2015 calendar year to 2,222,446 [63]. Lastly, data from Illinois' PDMP integration with EHRs at Anderson Hospital suggest that increase in PDMP report resulting from the integration 
was associated with decreased opioid prescribing [63]. It is worth noting there was a 145-fold increase in reports solicited by registered prescribers at the Anderson Hospital, from 6.9 reports per provider in 2013 to 998.2 per provider in 2015 [63]. In comparison, statewide number during the same period was 7.26 per provider in 2013 to 9.27 in 2015 [63]. Furthermore, there was a 22\% reduction in number of opioid prescriptions provided by Anderson Hospital provider compared with a $13 \%$ increase statewide during the same period [63]. There was also a $41 \%$ reduction in patients receiving at least one opioid prescription from Anderson Hospital providers compared with a $1 \%$ statewide increase [63].

In addition to the PDMP report integration with EHRs, PDS and HIEs, six of nine states were able to initiate interstate data sharing [63]. Illinois, Kansas and West Virginia achieved two-way interstate data exchange with three-quarters of their border states; the interstate data exchange expanded to include average of $90 \%$ of their border states for Indiana and Ohio [63]. There was a notable number of PDMP requests by in-state providers for out-of-state data [63]. Various other states are also making efforts to improve their PDMPs with goal of making the data content more meaningful to providers, easier to use and affect prescribing and utilization. According to McDonald [65], state of Rhode Island implemented PDMP "Dispenser Threshold Alerts" in 2017 that include alerts on use of more than 3 prescribers and pharmacies in the previous 6 months, morphine milligram equivalent greater than 90mg per day, overlapping opioid and benzodiazepine prescriptions and continuous days of opioid. These clinical alerts are important in knowledge, risk and time management, public health interest and connects clinical alerts to existing regulations such as the Food and Drug Administration's black box warning regarding the risk of concurrent administration of opioid and a benzodiazepine $[65,66]$. There has been a gradual decrease in total number of clinical alerts from May 2017 through January 2018, and the Rhode Island Department of Health will continue to evaluate how the clinical alerts affect PDMP targeted medication utilization, prescribing and ease of use for providers [65].

The state of New Mexico like many other states utilizes the PDMP data to generate prescriber reports. The "New Mexico Prescription Monitoring Program Prescriber Feedback Report" compares a particular provider's 6 month controlled substance prescribing data to the average of other prescribers in the same specialty [42]. This report is generated in partnership with the State Board of Pharmacy and sent to prescribers who have 20 or more controlled substance patients in the review period [42]. The state of New Mexico cited PDMP challenges including individual patient identification, linking the PDMP report request and patients, linking prescribers who may have multiple DEA numbers and noted the importance of data validation [42].

Carolinas HealthCare System is a health system that consists of over 40 hospitals, over 900 care locations, over 15,000 clinicians and greater than 10 million annual encounters [67]. In order to address the prescription opioid abuse and overdoses, clinical decision support, prescription reporting with immediate medication utilization mapping (PRIMUM) was implemented within the electronic medical record (EMR) and tested to determine how it affects prescribing behaviors $[67,68]$. Upon selection of a controlled substance, the EMR searches patient's chart for risk factors defined within the system; if a risk factor is identified, the EMR provides an alert and gives the provider an option to continue to prescribe or discontinue the prescription [67]. The EMR also has a direct hyperlink to the North Carolina and South Carolina PDMP [67]. Risk factor triggers such 
as early refills, previous history of opiate or benzodiazepine overdose, and a positive screening for cocaine and marijuana were selected based on literature review [67]. This study determined that the alerts had moderate effect resulting in $13-25 \%$ of prescriptions cancelled and the effect on the behavior varied by specialty [67]. The Carolinas HealthCare System has plans to further analyze the data and collaborate with the North Carolina and South Carolina PDMPs for integration [67].

\section{Limitations}

Due to the substantial number of literatures available on the subject of opioid epidemic and PDMPs, only a small sample was selected for review and does not represent complete spectrum of available views and findings. In addition, due to the variability in PDMP mandates by state, only a small sample was selected as examples.

\section{Conclusion}

The World Health Organization (WHO) defines health as "a state of complete physical, mental and social well-being and not merely the absence of disease or infirmity [69]." Recent tragic death of the legendary musician Prince at the age of 57 brought to light the indiscriminate effect of opioid addiction and overdose deaths; it was determined that Prince died of fentanyl overdose, taking what he thought was Vicodin but actually laced with fentanyl [70]. It is clear that the U.S. opioid epidemic has a tremendous impact on public health that not only affects the adults in this country but also the next generation.

Given the statistics and studies that suggest many of the illicit opioid users start with prescription opioids, continued advancement in the area of PDMP integration and interoperability is necessary. PDMPs are valuable tools for providers in making informed prescribing decisions. However, variability in state mandates and varying degrees of integration and interoperability across states may limit their usefulness as decision support tools. For example, a provider in a state that requires pharmacies to submit the controlled substance dispensing information within 24 hours may not see the prescriptions filled on the same day from other prescribers at different pharmacies on the PDMP report. Moreover, the prescriber may need to log in each time to obtain a PDMP report which may disrupt his/her workflow and become a deterrent for consistent use.

For PDMPs to be meaningful clinical decision support tool for prescribing decisions and data source for public health departments to inform targeted interventions, complete and consistent real time data is necessary. Furthermore, they need to be simple, efficient and integrated into the healthcare providers' workflow, interoperable with other systems such as EHRs, EMRs, and HIE and scalable. The PDMP integrated clinical decision support systems need to supply to healthcare providers access to complete, timely and evidence-based information that can meaningfully inform prescribing decisions and communication with patients that affect measurable outcomes. Sharing best practices, challenges and lessons learned among states and organizations may inform strategic and systematic use of PDMPs to improve public health outcomes. As with other system development or enhancement efforts, stakeholder engagement, particularly end-user engagement and participation are crucial; privacy, security, and HIPAA considerations must also be a priority. 


\section{References}

1. U.S. Department of Health \& Human Services [Internet]. Washington, D.C.: HHS; 2017 Oct 26 [cited 2019 Apr 5]. HHS Acting Secretary Declares Public Health Emergency to Address National Opioid Crisis; [about 1 screen]. Available from: https://www.hhs.gov/about/news/2017/10/26/hhs-acting-secretary-declares-public-healthemergency-address-national-opioid-crisis.html

2. Centers for Disease Control and Prevention [Internet]. Atlanta: The Center; 2018 Dec 19 [cited 2019 Apr 5]. Opioid Overdose: Understanding the Epidemic; [about 2 screens]. Available from: https://www.cdc.gov/drugoverdose/epidemic/index.html

3. Centers for Disease Control and Prevention [Internet]. Atlanta: CDC; 2018 Dec 19 [cited 2019 Apr 5]. Opioid Overdose: Prescription Opioid Data; [about 5 screens]. Available from: https://www.cdc.gov/drugoverdose/data/prescribing.html

4. Rudd RA, Aleshire N, Zibbell JE, Gladden RM. Increases in Drug and Opioid Overdose Deaths - United States, 2000-2014. Morb Mortal Wkly Rep [Internet]. 2016 Jan [cited 2019 Apr 4];64(50): [about 1100 p.] Available from https://www.cdc.gov/mmwr/preview/mmwrhtml/mm6450a3.htm?s_cid=mm6450a3_w

5. Vivolo-Kantor AM, Seth P, Gladden RM, Mattson CL, Baldwin GT, et al. 2018. Vital Signs: Trends in Emergency Department Visits for Suspected Opioid Overdoses - United States, July 2016-September 2017. MMWR Morb Mortal Wkly Rep. 67(9), 279-85. doi:. PubMed https://doi.org/10.15585/mmwr.mm6709e1

6. National Institute on Drug Abuse [Internet]. Bethesda: NIDA; 2018 Jun [cited 2019 Apr 5]. Prescription Opioids; [about 1 screen]. Available from: https://www.drugabuse.gov/publications/drugfacts/prescription-opioids

7. Centers for Disease Control and Prevention [Internet]. Atlanta: CDC; 2017 Aug 29 [cited 2019 Apr 5] Opioid Overdose: Prescription Opioids; [about 4 screens]. Available from: https://www.cdc.gov/drugoverdose/opioids/prescribed.html

8. Centers for Disease Control and Prevention [Internet]. Atlanta: CDC; 2018 Dec 19 [cited 2019 Apr 5]. Opioid Overdose: Heroin Overdose Data; [about 4 screens]. Available from: https://www.cdc.gov/drugoverdose/data/heroin.html

9. Centers for Disease Control and Prevention [Internet]. Atlanta: CDC; 2018 Dec 19 [cited 2019 Apr 5]. Opioid Overdose: Heroin; [about 4 screens]. Available from: https://www.cdc.gov/drugoverdose/opioids/heroin.html

10. Centers for Disease Control and Prevention [Internet]. Atlanta: CDC; 2018 Dec 19 [cited 2019 Apr 5]. Opioid Overdose: Fentanyl; [about 3 screens]. Available from: https://www.cdc.gov/drugoverdose/opioids/fentanyl.html 
11. Centers for Disease Control and Prevention [Internet]. Atlanta: CDC; 2018 Dec 19 [cited 2019 Apr 5]. Opioid Overdose: Fentanyl Overdose Data; [about 4 screens]. Available from: https://www.cdc.gov/drugoverdose/data/fentanyl.html

12. American Addiction Centers [Internet]. San Diego: Drugabuse.com; c2019 [cited 2019 Apr 5]. Let's Talk About the Elephant Tranquilizer in the Room; [about 1 screen]. Available from: https://drugabuse.com/lets-talk-about-the-elephant-tranquilizer-in-the-room/

13. Centers for Disease Control and Prevention [Internet]. Atlanta: CDC; 2018 Dec 19 [cited 2019 Apr 5]. Opioid Overdose: Opioid Data Analysis and Resources; [about 1 screens]. Available from: https://www.cdc.gov/drugoverdose/data/analysis.html

14. Dasgupta N, Beletsky L, Ciccarone D. 2018. Opioid Crisis: No Easy Fix to Its Social and Economic Determinants. Am J Public Health. 108(2), 182-86. Epub Feb. 2018. doi:. PubMed https://doi.org/10.2105/AJPH.2017.304187

15. Harvard TH. Chan School of Public Health [Internet]. Boston: The School; c2019 [cited 2019 Apr 5]. U.S. life expectancy drops again; [about 1 screen]. Available from: https://www.hsph.harvard.edu/news/hsph-in-the-news/u-s-life-expectancy-drops-again/

16. Bernstein LUS. life expectancy declines again, a dismal trend not seen since World War I. The Washington Post [Internet]. 2018 Nov 29 [cited 2019 Apr 5]. Available from: https://www.washingtonpost.com/national/health-science/us-life-expectancy-declines-againa-dismal-trend-not-seen-since-world-war-i/2018/11/28/ae58bc8c-f28c-11e8-bc79-

68604ed88993_story.html?noredirect=on\&utm_term=.012ce23f4c6a

17. Gostin LO, Hodge JG, Noe SA. 2017. Reframing the Opioid Epidemic as a National Emergency. JAMA. 318(16), 1539-40. doi:. https://doi.org/10.1001/jama.2017.13358

18. Jilani SM, Frey MT, Pepin D, Jewell T, Jordan M, et al. 2019. Evaluation of State-Mandated Reporting of Neonatal Abstinence Syndrome - Six States, 2013-2017. MMWR Morb Mortal Wkly Rep. 68(1), 6-10. doi:. PubMed https://doi.org/10.15585/mmwr.mm6801a2

19. Feder KA, Letourneau EJ, Brook J. Children in the Opioid Epidemic: Addressing the Next Generation's Public Health Crisis. Pediatrics [Internet]. 2019 Jan [cited 2019 Apr 4];143(1): [about 1 p.]. Available from: https://pediatrics.aappublications.org/content/143/1/e20181656

20. Khoury L, Tang YL, Bradley B, Cubells JF, Ressler KJ. 2010. Substance use, childhood traumatic experience, and Posttraumatic Stress Disorder in an urban civilian population. Depress Anxiety. 27(12), 1077-86. doi:. PubMed https://doi.org/10.1002/da.20751

21. Srivastava AB, Gold MS. Missed opportunities: Opioid overdoses and suicide. Clinical Psychiatry News [Internet]. 2017 Aug 29 [cited Apr 6] Available from: https://www.mdedge.com/psychiatry/article/145653/addiction-medicine/missedopportunities-opioid-overdoses-and-suicide 
22. Park TW, Lin LA, Hosanagar A, Kogowski A, Paige K, et al. 2016. Understanding risk factors for opioid overdose in clinical populations to inform treatment and policy. $J$ Addict Med. 10(6), 369-81. PubMed https://doi.org/10.1097/ADM.0000000000000245

23. International Association of Fire Fighters (IAFF). EMS Response to Opioid Overdose and Fire Fighter Health Center of Excellence. 2018 National Rx Drug Abuse \& Heroin Summit [PDF slides]; 2018 Apr 2-5; Atlanta, GA. Available from: https://swoogo.s3.amazonaws.com/uploads/124621-5ac4183472305.pdf

24. National Institute on Drug Abuse [Internet]. Bethesda: NIDA; 2019 Jan [cited 2019 Apr 6]. Prescription Opioids; [about 1 screen]. Available from: https://www.drugabuse.gov/drugsabuse/opioids/opioid-overdose-crisis

25. Public Broadcasting Service. How the opioid crisis decimated the American workforce. PBS News Hour [Internet]. 2017 Oct 5 [cited 2019 Apr 6]. Available from: https://www.pbs.org/newshour/show/opioid-crisis-decimated-american-workforce\#transcript

26. Burke J, Goplerud E, Hartley S. Real Costs of Rx Pain Meds, Opioids and Substance Use in the Workplace: What Employers and Communities Can Do. 2018 National Rx Drug Abuse \& Heroin Summit [PDF slides]; 2018 Apr 2-5; Atlanta, GA. Available from: https://swoogo.s3.amazonaws.com/uploads/123755-5ac0f531c5d31.pdf

27. Centers for Disease Control and Prevention [Internet]. Atlanta: CDC; 2017 Aug 31 [cited 2019 Apr 6]. Overdose Prevention: Opioid Overdose; [about 1 screen]. Available from: https://www.cdc.gov/drugoverdose/prevention/index.html

28. Centers for Disease Control and Prevention [Internet]. Atlanta: CDC; 2019 Apr 17 [cited 2019 May 6]. Opioid Overdose: CDC Guideline for Prescribing Opioids for Chronic Pain; [about 4 screens]. Retrieved from https://www.cdc.gov/drugoverdose/prescribing/guideline.html

29. Dowell D, Haegerich TM, Chou R. 2016. CDC Guideline for Prescribing Opioids for Chronic Pain--United States, 2016. JAMA. 315(15), 1624-45. doi: $\underline{\text { PubMed }}$ https://doi.org/10.1001/jama.2016.1464

30. Centers for Disease Control and Prevention [Internet]. Atlanta: CDC; 2017 Oct 11 [cited 2019 Apr 6]. Overdose Prevention: Prevent Opioid Use Disorder; [about 2 screens]. Available from: https://www.cdc.gov/drugoverdose/prevention/opioid-use-disorder.html

31. Centers for Disease Control and Prevention [Internet]. Atlanta: CDC; 2017 Aug 23 [cited 2019 Apr 6]. Opioid Overdose. Treat Opioid Use Disorder; [about 4 screens]. Available from: https://www.cdc.gov/drugoverdose/prevention/treatment.html

32. Substance Abuse and Mental Health Services Administration. [Internet]. Rockville: SAMHSA; 2019 [cited 2019 Apr 6]. Behavioral Health Treatment Services Locator; [about 1 screen]. Available from: https://findtreatment.samhsa.gov/ 
33. Centers for Disease Control and Prevention [Internet]. Atlanta: CDC; 2017 Aug 29 [cited 2019 Apr 6]. Opioid Overdose: Reverse Overdose to Prevent Death; [about 1 screen] Available from: https://www.cdc.gov/drugoverdose/prevention/reverse-od.html

34. U.S. Department of Health \& Human Services [Internet]. Washington, D.C.: HHS.GOV/OPIOIDS; 2018 Aug 7 [cited 2019 Apr 6]. 5-Point Strategy To Combat the Opioid Crisis; [about 1 screen]. Available from: https://www.hhs.gov/opioids/about-theepidemic/hhs-response/index.html

35. U.S. Department of Health \& Human Services [Internet]. Washington, D.C.: HHS.GOV/OPIOIDS; 2018 May 15 [cited 2019 Apr 6]. Better Prevention, Treatment \& Recovery Services; [about 1 screen]. Available from: https://www.hhs.gov/opioids/about-theepidemic/hhs-response/better-access/index.html

36. U.S. Department of Health \& Human Services [Internet]. Washington, D.C.: HHS.GOV/OPIOIDS; 2018 May 15 [cited 2019 Apr 6]. Better Data; [about 1 screen]. Available from: https://www.hhs.gov/opioids/about-the-epidemic/hhs-response/betterdata/index.html

37. U.S. Department of Health \& Human Services [Internet]. Washington, D.C.: HHS.GOV/OPIOIDS; 2018 May 15 [cited 2019 Apr 6]. Better Pain Management; [about 1 screen]. Available from: https://www.hhs.gov/opioids/about-the-epidemic/hhsresponse/better-pain-management/index.html

38. U.S. Department of Health \& Human Services [Internet]. Washington, D.C.: HHS.GOV/OPIOIDS; 2018 May 15 [cited 2019 Apr 6]. Better Availability of OverdoseReversing Drugs; [about 1 screen]. Available from: https://www.hhs.gov/opioids/about-theepidemic/hhs-response/better-overdose-response/index.html

39. U.S. Department of Health \& Human Services [Internet]. Washington, D.C.: HHS.GOV/OPIOIDS; 2018 May 15 [cited 2019 Apr 6]. Better Research. Available from: https://www.hhs.gov/opioids/about-the-epidemic/hhs-response/better-research/index.html

40. National Institute on Drug Abuse [Internet]. Bethesda: NIDA; 2019 Jan [cited 2019 Apr 7]. Dramatic Increases in Maternal Opioid Use and Neonatal Abstinence Syndrome; [about 1 screen]. Available from: https://www.drugabuse.gov/related-topics/trendsstatistics/infographics/dramatic-increases-in-maternal-opioid-use-neonatal-abstinencesyndrome

41. Seth P, Vivolo-Kantor AM, O'Donnell J. Faster Data: The CDC-Funded Enhanced State Opioid Overdose Surveillance Program (ESOOS). 2018 National Rx Drug Abuse \& Heroin Summit [PDF slides]; 2018 Apr 2-5; Atlanta, GA. Available from: https://swoogo.s3.amazonaws.com/uploads/123687-5ac0d4a007da5.pdf

42. Singleton M, Saavedra LG, Broad J. States with Fast Data: Lessons Learned from Kentucky, New Mexico and Wisconsin. 2018 National Rx Drug Abuse \& Heroin Summit [PDF slides]; 
2018 Apr 2-5; Atlanta, GA. Available from: https://swoogo.s3.amazonaws.com/uploads/123720-5ac0f08038fc5.pdf

43. Dunlap LJ. Expanding Access to Treatment for Opioid Use Disorder (OUD): The Role of Telehealth. 2018 National Rx Drug Abuse \& Heroin Summit [PDF slides]; 2018 Apr 2-5; Atlanta, GA. Available from: https://swoogo.s3.amazonaws.com/uploads/1237475ac0f42717ad5.pdf

44. Yellowlees P. Telemedicine for Opioid Use Disorder. 2018 National Rx Drug Abuse \& Heroin Summit [PDF slides]; 2018 Apr 2-5; Atlanta, GA. Available from https://swoogo.s3.amazonaws.com/uploads/123747-5ac0f42717ad5.pdf

45. Zheng W, Nickasch M, Lander L, Wen S, Xiao M, et al. 2017. Treatment Outcome Comparison Between Telepsychiatry and Face-to-face Buprenorphine Medication-assisted Treatment for Opioid Use Disorder: A 2-Year Retrospective Data Analysis. J Addict Med. 11(2), 138-44. doi:. PubMed https://doi.org/10.1097/ADM.0000000000000287

46. Humphreys K. Americans use far more opioids than anyone else in the world. The Washington Post [Internet]. 2017 Mar 15 [cited 2019 Apr 7]. Available from: https://www.washingtonpost.com/news/wonk/wp/2017/03/15/americans-use-far-moreopioids-than-anyone-else-in-the-world/?utm_term $=.0 \mathrm{fbfb} 0 \mathrm{c} 86 \mathrm{f} 30$

47. Humphreys K. Americans take more pain pills but not because they are in more pain. The Washington Post [Internet]. 2018 Mar 23 [cited 2019 Apr 7]. Available from: https://www.washingtonpost.com/news/wonk/wp/2018/03/23/americans-take-more-painpills-but-not-because-theyre-in-more-pain/?utm_term=.5aea8e534bb3

48. Office of Inspector General. Opioids in Medicare Part D: Concerns about Extreme Use and Questionable Prescribing. HHS OIG Data Brief [Internet]. 2017 Jul [cited 2019 Apr 7]; [about 10 p.]. Available from: https://oig.hhs.gov/oei/reports/oei-02-17-00250.pdf

49. Centers for Disease Control and Prevention [Internet]. Atlanta: CDC; 2019 [cited 2019 Apr 5]. Trends in Annual Opioid Prescribing Rates by Overall and High-Dosage Prescriptions; [about 1 screen]. Available from: https://www.cdc.gov/TemplatePackage/contrib/widgets/cdcCharts/iframe.html?chost=www. cdc.gov\&cpath=/drugoverdose/data/prescribing.html\&csearch $=\&$ chash $=\&$ ctitle=Prescriptio n\%20Opioid\%20Data\%20\%7C\%20Drug\%20Overdose\%20\%7C\%20CDC\%20Injury\%20Ce nter\&wn=cdcCharts\&wf=/TemplatePackage/contrib/widgets/cdcCharts/\&wid=cdcCharts1\& mMode $=$ widget $\& \mathrm{mPage}=\& \mathrm{mChannel}=\&$ host $=\mathrm{www} . \mathrm{cdc} \cdot \operatorname{gov} \&$ displayMode $=\mathrm{w} \mathrm{cms} \& \operatorname{config}$ $\mathrm{Url}=/$ drugoverdose/data/TrendsChart.json\&class $=\mathrm{mb}-3$

50. Centers for Disease Control and Prevention [Internet]. Atlanta: CDC; 2018 Oct 3 [cited 2019 Apr 5]. Opioid Overdose: U.S. Opioid Prescribing Rate Maps; [about 1 screen]. Available from: https://www.cdc.gov/drugoverdose/maps/rxrate-maps.html 
51. Nelson LS, Juurlink DN, Perrone J. 2015. Addressing the Opioid Epidemic. JAMA. 314(14), 1453-54. doi:. PubMed https://doi.org/10.1001/jama.2015.12397

52. Center Centers for Disease Control and Prevention [Internet]. Atlanta: CDC; 2017 Oct 3 [cited 2019 Apr 7]. Opioid Overdose: What States Need to Know about PDMPs; [about 1 screen]. Available from: https://www.cdc.gov/drugoverdose/pdmp/states.html

53. McDonald JV. What do you do, when a patient violates a pain agreement? Rhode Island Department of Public Health [Internet]. 2015 Jun 10 [cited 2019 Apr 7]; [about 10 p.]. Available from: http://www.health.ri.gov/publications/guidelines/provider/PatientViolatesPainAgreement.pd $\mathrm{f}$

54. Kolodny A. Changing Prescribing Practices to Prevent Opioid Addiction. 2018 National Rx Drug Abuse \& Heroin Summit [PDF slides]; 2018 Apr 2-5; Atlanta, GA. Available from: https://swoogo.s3.amazonaws.com/uploads/123732-5ac0f21bf0064.pdf

55. Volkow ND, McLellan TA, Cotto JH, Karithanom M, Weiss SR. 2011. Characteristics of opioid prescriptions in 2009. JAMA. 305(13), 1299-301. doi: $\underline{\text { PubMed }}$ https://doi.org/10.1001/jama.2011.401

56. Miech R, Johnston L, O’Malley PM, Keyes KM, Heard K. 2015. Prescription Opioids in Adolescence and Future Opioid Misuse. Pediatrics. 136(5), e1169-77. doi:. PubMed https://doi.org/10.1542/peds.2015-1364

57. PEW [Internet]. Philadelphia: The PEW Charitable Trusts; c1996-2019 [cited 2019 Apr 7]. When are Prescribers Required to use Prescription Drug Monitoring Programs? Data show mandates vary across states; [about 1 screen]. Available from: https://www.pewtrusts.org/en/research-and-analysis/data-visualizations/2018/when-areprescribers-required-to-use-prescription-drug-monitoring-programs

58. AZ.Gov. [Internet]. Phoenix: Arizona State Board of Pharmacy; 2019 [cited 2019 Apr 7]. Available from https://pharmacypmp.az.gov/

59. Appriss Health [Internet]. Data Submission Guide for Dispensers. Michigan Automated Prescription System. 2019 Mar [cited 2019 Apr 7]; [about 3 p.]. Available from: https://www.michigan.gov/documents/lara/MI_Data_Submission_Dispenser_Guide_576262 -7.pdf

60. Rasubala L, Pernapati L, Velasquez X, Burk J, Ren YF. 2015. Impact of a Mandatory Prescription Drug Monitoring Program on Prescription of Opioid Analgesics by Dentists. PLoS One. 10(8), e0135957. doi:. PubMed https://doi.org/10.1371/journal.pone.0135957

61. Paulozzi LJ, Kilbourne EM, Desai HA. 2011. Prescription Drug Monitoring Programs and Death Rates from Drug Overdose. Pain Med. 12(5), 747-54. doi: $\underline{\text { PubMed }}$ https://doi.org/10.1111/j.1526-4637.2011.01062.x 
62. Patrick SW, Fry CE, Jones TF, Buntin MB. 2016. Implementation Of Prescription Drug Monitoring Programs Associated With Reductions In Opioid-Related Death Rates. Health Aff (Millwood). 35(7), 1324-32. Epub Jun 2016. doi:. https://doi.org/10.1377/hlthaff.2015.1496

63. Centers for Disease Control and Prevention [Internet]. Integrating \& Expanding Prescription Drug Monitoring Program Data: Lessons from Nine States. 2017 Feb [cited 2019 Apr 7]; [about 12 p.]. Available from https://www.cdc.gov/drugoverdose/pdf/pehriie_report-a.pdf

64. Bridwell L, Sargent W, Murzynski S, Vinciguerra J. Advancing Science Into Action: Enhancing PDMPs and EHRs. 2018 National Rx Drug Abuse \& Heroin Summit [PDF slides]; 2018 Apr 2-5; Atlanta, GA. Available from: https://swoogo.s3.amazonaws.com/uploads/123719-5ac0f065ef827.pdf

65. McDonald JV. Rhode Island Prescription Drug Monitoring Clinical Alerts: Preliminary Effects on Prescribing. 2018 National Rx Drug Abuse \& Heroin Summit [PDF slides]; 2018 Apr 2-5; Atlanta, GA. Available from: https://swoogo.s3.amazonaws.com/uploads/1237145ac0ef78c9035.pdf

66. U.S. Food \& Drug Administration. FDA requires strong warnings for opioid analgesics, prescription opioid cough products, and benzodiazepine labeling related to serious risks and death from combined use. FDA News Release [Internet]. 2016 Aug 31 [cited 2019 Apr 7]. Available from: https://www.fda.gov/news-events/press-announcements/fda-requires-strongwarnings-opioid-analgesics-prescription-opioid-cough-products-and-benzodiazepine

67. Losby J, Wally M, Hsu J. Using EHR-Based Clinical Decision Supports to Affect Opioid Prescribing Behavior. 2018 National Rx Drug Abuse \& Heroin Summit [PDF slides]; 2018 Apr 2-5; Atlanta, GA. Available from: https://swoogo.s3.amazonaws.com/uploads/1237305ac0f1d799386.pdf

68. Seymour RB, Leas D, Wally MK, Hsu JR. 2016. PRIMUM Group. Prescription reporting with immediate medication utilization mapping (PRIMUM): development of an alert to improve narcotic prescribing [Erratum in: BMC Med Inform Decis Mak. 2016;16] [1] [:125. PubMed PMID: 27549364; PubMed Central PMCID: PMC4994311]. BMC Med Inform Decis Mak. 16(1), 125. doi:. PubMed https://doi.org/10.1186/s12911-016-0364-6

69. World Health Organization [Internet]. Geneva: WHO; 2019 [cited 2019 Apr 7]. Constitution; [about 1 screen]. Available from https://www.who.int/about/who-we-are/constitution

70. Silva D. Prince died after taking fake Vicodin laced with fentanyl, prosecutor says. NBC News [Internet]. April 19. 2018 Apr 19 [cited 2019 Apr 7]. Available from: https://www.nbcnews.com/news/us-news/no-criminal-charges-prince-s-overdose-deathprosecutor-announces-n867491 